DOI https://doi.org/10.30525/978-9934-588-37-2.1.11

\title{
MODERN ADOLESCENTS' PSYCHOLOGICAL WELL-BEING AND SOCIAL MEDIA OVERLOAD
}

\section{Hudimova A. Kh.}

\section{INTRODUCTION}

Social media are an integral part of everyone's life, but they are the most popular among the younger generation. Therefore, because of the adolescents' involvement in various social media applications, the question of the relationship between their use and psychological health, including well-being, becomes crucial. The most active users are young people between the ages of 15 and 28 . This age period is the most important in terms of psychological and emotional development, so studying the impact of social media is necessary. In the current rhythm of society, social media become a platform for building relationships, forming one's own identity, expressing oneself, and exploring the culture and specifics of other users' lives.

As a result of the analysis of the scientific literature, it was found that external factors (interlocutor distance, non-contact, etc.) tend to mask the psychological characteristics of users of social networks and to compensate for communication barriers. However, there are enough studies that reveal the negative effects of virtual communication, such as internet addiction, autism, gambling, inappropriate effects in the process of social perception.

Profile designing and being active on various online platforms help adolescents become part of certain virtual societies, self-actualize, and establish themselves in the eyes of peers as long as their account is popular. Social media can promote communication and emotional support among users. With their ability to connect people around the world, social media can potentially have a positive impact on mental health. However, some risks can lead to serious mental, psychological and well-being problems in adolescence.

The subject of this study is the impact of social media on the psychological well-being of adolescents. A review and analysis of the literature have shown that most of the existing studies show a complex link between social networking and psychological well-being. This pattern is due to several factors, which include: the number of 'friends', the level of support for online friends, loneliness, depression, and self-esteem. The use of social media has the effect of reducing the two components of psychological well-being: the current state and overall satisfaction with life. 
An empirical study was conducted to identify the specific impact of social media on adolescents' psychological well-being. The research process involved the use of specialized diagnostic material and mathematical statistics methods to analyze and interpret the results. The participants for this study were 262 students from college and university of Odesa (Ukraine). Participants completed a survey designed to measure overall well-being and broad aspects of well-being that included the WHO-5 Well-being Index, The Warwick-Edinburgh Mental Wellbeing Scale (WEMWBS), Questionnaire to determine the type of loneliness, Freiburg personality inventory test.

\section{Psychological features of adolescents' relationships in social media}

The theoretical review has made it clear that in the 21 st century, two comprehensive areas are used for the study of psychological well-being: one focuses on happiness and the other focuses on individual potential ${ }^{1}$. Happiness is classified as subjective well-being, whereas psychological well-being is directly related to one's personal growth and life purpose.

The impact of virtual communication on psychological well-being is mediated by a set of personal characteristics that are specific to each individual, namely psychological functioning, capabilities, culture, and attitudes. Therefore, the interaction between people's activities in different walks of life and their attributes explains why the use of the Internet has mixed implications for different individuals and social groups.

A literature review has shown that research into the impact of social networking on psychological well-being should take into account three important heterogeneous factors. Firstly, the effects of using virtual space vary depending on specific personal characteristics and conditions that shape users' perceptions of their status and well-being (opportunities, psychological functioning, culture, and beliefs). Secondly, social media can have different effects on the individual well-being mentioned above: hedonistic or eudemonic. Thirdly, since social media include a wide range of different applications, their impact on human well-being will depend on the particular type of application (watching news feeds, videos, listening to music, messaging, etc.).

The term 'social network' was first produced by James Barnes in his work "Classes and Assemblies" in the Norwegian Island Parish in 1954. In the article by K.S. Weber and A.O. Pimenov is given the following interpretation of the term: "Social networking service - a platform, online

${ }^{1}$ Deci E. L. and Ryan R. (2008). M. Self-determination theory: a macrotheory of human motivation, development, and health. Canadian Psychology-Psychologie Canadienne. № 49(3). URL: https://doi.org/10.1037/0708-5591.49.1.14. 
service or web site designed to build, display and organize social relationships, visualized by social graphs" ${ }^{\text {. }}$.

Social networks or social media are a social structure made up of core groups, of which individuals and groups are part. A feature of any social media is the presence of a system of friends, so they are often used to find previously acquaintances, people with similar interests ${ }^{3}$.

Communication in the network allows adolescents to acquire social knowledge and accumulate social experience. Social media are a platform for personality transformation that significantly expands boundaries and removes barriers to communication. Communication is established fast enough and users can easily get feedback. Social media among adolescents are becoming a priority means of communication, which is a considerable distance from real social roles. In the process of becoming self-aware, the adolescents begin to create their personality, find their place in the process of interpersonal communication, in which the uniqueness of the person in social media turns to reflected in the 'mirror' of other consciousness image of their 'I'. Due to excessive cyber-socialization and increasing time spent online, it is appropriate to question the relationship between the real self and the virtual personality.

Social media communication has both positive and negative consequences. This type of relationship contributes to broadening experience, enhancing social competence, meeting group membership needs, and self-disclosure. Among the negative consequences of this process are the diffusion of identity, excessive Internet access, called 'Internet addiction'

Some researchers associate the use of social media with individual characteristics of users. People with high levels of narcissism try to be as active on social media as the latter is a platform for presenting themselves in a favorable light according to their ideal ' $\mathrm{I}$ '.

$\mathrm{K}$. Wilson and colleagues found that such personal characteristics as extraversion, honesty, and self-esteem allow us to predict both the amount of time spent on social networks and the propensity to form addiction ${ }^{6}$.

${ }^{2}$ Вебер К.С., Пименова А.А. Сравнительный анализ социальных сетей. Вестник ТГУ. 2014. Т. 19, вып. 2. С. 634-635.

Бабаева Ю.Д., Войскунский А.Е., Смыслова О.В. Интернет: воздействие на личность.

${ }^{4}$ Войскунский А.Е. Психология и Интернет. Москва : Акрополь, 2010. 439 с.

${ }^{5}$ Buffardi, E. L., \& Campbell, W. K. (2008). Narcissism and social networking web sites. Personality and Social Psychology Bulletin, 34, 1303-1314. URL: https://doi.org/10.1177/0146167208320061.

${ }^{6}$ Wilson, K., Fornasier, S., \& White, K. M. (2010). Psychological predictors of young adults' use of social networking sites. Cyberpsychology, Behavior, and Social Networking, 13, 173-177. URL: https://doi.org/10.1089/cyber.2009.0094. 
Excessive and problematic use of social media is associated with several potential negative consequences for the psychological well-being of adolescents. The most common are substance abuse, attention deficit hyperactivity disorder, loneliness, depression, and poor communication skills. Besides, there are several online risk groups that adolescents often encounter: content, communication, consumer and technical ${ }^{7}$.

Adolescents often apply to social media as a means of emotional support to prevent and address mental health problems. Conversations can be a great support for overcoming psychological problems, especially when there is no one to share with in real life ${ }^{8}$. A high level of involvement in social media is associated with a low level of social loneliness but at the same time an increased level of emotional loneliness.

Social media continue to change the nature of communication between individuals and transform relationships. Turkle's research has shown that new technologies and social media lead to the formation of new, unhealthy relationships between parents, children, friends, and others. Such changes also lead to negative consequences for community understanding, privacy, and closeness ${ }^{9}$.

Therefore, the popularity of social media is spreading at a rapid pace among adolescents and, as a paradox, the current younger generation is more lonely, unlike other age groups. In this context, loneliness is seen as the difference between the desired and the real level of social contact. Uncontrolled, unhygienic and persuasive use of social networks enhances loneliness ${ }^{10}$.

The fragmentation of researches on the impact of social media on psychological well-being, the formation of addiction and even social disorder can be explained by the following reasons. Firstly, the situation with social media is quite volatile, as existing ones are often supplemented by new features or new ones are introduced into the market, which causes them to become more interested. Secondly, existing standards and diagnostic tools have different criteria for assessing the presence of addiction or disorder, which in turn stimulates an even greater gap in the degree of

${ }^{7}$ Цифрова компетентність підлітків та батьків. / Г.У. Солдатова, Т.А. Нестик, Е.І. Расказова, Е.Ю. Зотов. Москва : Фонд розвитку Інтернету, 2013. 144 с.

${ }^{8}$ Farnan JM, Snyder SL, Worster BK, et al. Online medical professionalism: patient and public relations: policy statement from the American College of Physicians and the Federation of State Medical Boards. Ann Intern Med. 2013; 158 (8): 620-62. 10.7326/0003-4819-158-8-201304160-00100.

9 Turkle, S. (2011) Alone Together: Why we expect more from technology and less from each other. New York : Basic Books. URL: https://doi.org/10.1002/asi.22658.

10 Yao, M. Z., \& Zhong, Z. J. (2014). Loneliness, social contacts and Internet addiction: A cross-lagged panel study. Computers in Human Behavior, 30, 164-170. https://doi.org/10.1016/j.chb.2013.08.007. 
elaboration of the problem. Therefore, it is important to make progress in studying the impact of social media on psychological health by creating and validating diagnostic tools based on commonly accepted assessment criteria.

The theoretical models analyzed explain the emergence of psychological well-being disorders in connection with the use of social media in terms of medical and biopsychosocial approaches.

Analysis of the literature allowed us to formulate the following hypotheses, which were tested in this study:

H1. Prolonged stay in social media leads to psychological disorders, including sleep disorders, stress, depression.

H2. The advantage of virtual communication is associated with the illusion of suppression of social loneliness' feelings.

H3. The psychological well-being of adolescents depends not only on the users with whom they interact but also on the content of social media.

H4. Shy adolescents use social media as a platform to express themselves / escape from reality rather than increase social contact.

\section{Determination of the psychological well-being of adolescents as social media users}

Study was conducted in two steps. In the first stage of the study, 60 students aged 15-21 years old were surveyed. To collect data on the socio-demographic characteristics of adolescents, a specially designed questionnaire was used, the Freiburg Personality Inventory $-\mathrm{B}^{11}$, the WHO-5 Well-being Index was used to study the psychological and individual sphere ${ }^{12,13}$. Questionnaire to determine the type of loneliness ${ }^{14}$. The questionnaire consisted of multiple-choice, rating scales (e.g. Likert scale) and closed-ended questions.

According to the data obtained, the average time spent by respondents on social media is more than four hours a day. This pattern is associated with the need for adolescents to be involved in the community, to feel less alone, to share important information with the world, and to seek out like-minded people. Excessive use of social media can lead to cognitive-emotional anxiety, impaired self-esteem, and other psychological problems. With

${ }^{11}$ Fahrenberg, J., Hampel, R. \& Selg, H. (2010). Freiburger Persönlichkeitsinventar (8., erweiterte Aufl.). Göttingen: Hogrefe.

${ }_{12}$ Bech P. (2004). Measuring the dimensions of psychological general well-being by the WHO-5. QoL Newsletter, 32, 15-16.

${ }^{13}$ Topp, Christian \& Østergaard, Søren \& Søndergaard, Susan \& Bech, Per. (2015). The WHO-5 Well-Being Index: A systematic review of the literature. Psychotherapy and psychosomatics, 84, 167-176. URL: https://doi.org/10.1159/00037658.

14 Корчагина С.Г. Психология одиночества : учебное пособие. Москва : Московский психолого-социальный институт, 2008. 228 с. 
increasing time spent on virtual communication, the risks of becoming a victim of cyberbullying, conflict of the real and ideal 'I', loss of an adequate mechanism of communication increases loneliness. Usually, social media affect the relationship between children and parents, which in some cases leads to conflict. The benefits of using social media in family relationships are keeping in touch with children at a distance. Video chatting, messaging, and sharing photos of family living far apart can reduce this distance. The disadvantages are that adolescents usually share their feelings, problems with 'friends' on the Internet; since the need to share information is satisfied, the conversations or advice of parents become irrelevant. This can lead to a deterioration of family ties. Our study found that adolescents prefer to share their problems and ask for help from family, not from virtual 'friends' $(1.52 \pm 0.701)$. As a result of the survey, we were able to find out that there were no problems in the relations with their parents due to the use of social media $(4.17 \pm 0.942)$. Social networking enthusiasm, accompanied by the presence of accounts on several online platforms, is linked to the possibility of adolescents to strengthen their existing friendship and form a new one. A variety of social networking services, including messengers (Viber, WhatsApp), Twitter, Facebook, Instagram, Snapchat, Pinterest, allow adolescents to explore and shape their identity by choosing what information, aspects of themselves to share, including which audience. The feelings of affirmation and acceptance they receive are important for developing healthy self-esteem and positive well-being. However, it is not so easy in cyberspace. In trying to get as much positive feedback as possible, adolescents often go through considerable difficulty exiting social networks $(3.05 \pm 0.839)$. This, in turn, affects interpersonal relationships, sleep patterns, and academic performance. Another negative aspect of self-presentation on the web for psychological well-being is cyberbullying. The most common manifestations of the latter that adolescents face are: spreading rumors or sending hateful messages; creating humiliation profiles; distribute inappropriate photos or videos and send threatening or abusive messages. The main purpose of social networks is to create the conditions for communication, however, according to our study, most of the time adolescents spend not communicating with others, but 'scroll' or browse the news feed $(2.03 \pm 0.99)$. Due to the creation of new features and capabilities of social networking applications, adolescents prefer non-verbal communication through reactions such as 'likes', stickers, video recording, etc. Being able to create an account in a fictitious way or anonymously publish a post that can share problems, experiences, and seeking help is often the fastest way to find a solution to the difficult life situations of adolescents. We have found that, in rare cases, respondents prefer social media to reality and as a means of escape from difficulties. 
A mediocre profile has revealed that modern adolescents prefer to chat with real-life people rather than new 'friends'. Social media have changed the nature of engagement. Some adolescents are partially unable to talk or interact with people personally because of their dependency on social media. Social media are becoming one of the dominant means of communication. Virtual communication affects not only mental health, including psychological well-being but also physical health. Social media can be a platform to provide access to medical information, about other people's health and well-being, and to provide emotional support. The downside is that gadgets 'crowd out' other adolescents' activities (exercise, real communication, or reading books). Based on the results obtained, it can be concluded that among the interviewed respondents, sleep disorders due to the use of social networks occur very rarely $(3.67 \pm 1,100)$.

The specificity of social media is the ability to create a 'new' personality, which is more free and relaxed than in real life. Overly passionate about online image support, adolescents can lead two separate lives in reality and cyberspace. Over time, adolescents begin to feel pressure in terms of their virtual image, presented in the form of pictures on social media. The mismatch of the real image to the more popular virtual becomes a serious source of stress. As a result of mathematical processing, it was found that adolescents, although concerned with the number of 'likes' and 'followers', but this does not lead to pronounced manifestations of stress $(2.57 \pm 1,419)$. Adolescents spend their time on social media both for entertainment purposes and to become involved in the community. Paradoxically, virtual communication does not remove the feeling of loneliness, but only produces it. Thus, the study found that adolescents experience a loss of inner integrity and a mismatch of the desired and actual quality of communication $(7.30 \pm 2.739)$. The presence of diffuse loneliness is associated with the impersonal communication of the network, the alienation of one's self. The alienation of loneliness as a result of the social media's overuse is characterized by loss of significant connections and contacts, in particular intimacy and privacy in communication, tendency to be lonely. The emergence of dissociated loneliness is caused by conflicts due to the opinion that adolescents are forced to live by the set rules, and their identity is ignored altogether.

The relationship between virtual communication and the average level of psychological well-being is because this method is a weak form of interaction that can increase the risk of depression and / or social exclusion. It was found that involvement in social media does not lead to hopelessness in adolescents $(0.75 \pm 1.525)$. Due to the excessive amount of time spent in the virtual dimension, communicating through smartphones, adolescents tend to neuroticism $(6,30 \pm 1,960)$. This phenomenon is manifested in the 
tendency to feel negative emotional states, which are accompanied by increased anxiety or depression, anger, and guilt, as well as an increased tendency to somatization of psychological problems. This emotionally unstable and impulsive nature in combination with low self-control is associated with a high level of 'phubbing', that is, checking adolescents' smartphone in the middle of a real conversation to miss out on social networking apps. Frequent overuse of social media is associated with the externalization of adolescents' problems, which manifests as spontaneous and reactive aggression. Characteristic signs of behavior are increased levels of impulsiveness, anger and hostility, general dissatisfaction with the environment. Because adolescents use social media passively most of the time, including browsing the news feed, we found an average level of depression, accompanied by feelings of loneliness, hopelessness, and feelings of inferiority. The average level of irritability indicates the tendency of adolescents to be more hostile, act impulsively or rudely with the least dissatisfaction with their own needs or with minor differences with others. Given the annoyance in the context of virtual communication, it is characterized by fear, anxiety and a sense of inconvenience when it is impossible to check for updates overtime on social media. Communicativeness is an integral part of user interaction on social media, but the level detected indicates the need for contacts, but most of the time in adolescents is not passive, but passive use of social media. Adolescents have a sufficient level of ability to manage themselves in stressful situations, but to ease their condition, they often turn to online 'friends' for help, mostly anonymously. To some extent, social media allow socializing to shy adolescents, helping to overcome some of the natural seclusion and stiffness. By using social media, adolescents can avoid direct conversations by interlocutors and thus reduce or prevent anxiety. However, by creating a comfortable social space, shy adolescents start spending more and more time online, which can lead to social disruption. Adolescents' openness $(7.27 \pm 1.885)$ on social media is inextricably linked to the number of likes, comments, group chats or dialogues, as well as status updates in all accounts with positive reactions from other users. The latter are positively reinforced to further generate more profitable content to present themselves on the best side. Among adolescents, the predominant ambiguous type is driven by the need and interpersonal contacts, and social media are an ideal platform for maintaining relationships with real acquaintances as well as for making new acquaintances. Due to the use of social media, adolescents have manifestations of irritability, mood swings, and lack of self-regulation. Concerning the masculinity-femininity scale of FPI-B $(4.70 \pm 2.212)$, it can be concluded that social media are necessary for adolescents to meet the needs of approval and to receive as much attention as possible. 
Manifestations include exhibiting a large number of selfies to self-present on the best side, which in turn affects psychological well-being. The need to maintain existing contacts and establish new ones is compounded by the tendency to hide your personal information. However, spending time online is irrational due to the 'need' to maintain the popularity of your online image.

During the survey, the respondents were divided into two groups, depending on the time spent on social media. Factor analysis for both groups was conducted to identify differences.

We have identified three factors as a result of rotation with the normalization of Varimax, which is shown in Table 1. The result suggested that adolescents who spend less than two hours a day on social media use the platform's data as entertainment. Due to skillful time management, without neglecting real life, this group has time to communicate and stay up to date on the latest news.

Table 1

The matrix of components after rotation of group No. 1 (time spent online - less than 2 hours per day)

\begin{tabular}{|l|c|c|c|}
\hline \multirow{2}{*}{\multicolumn{1}{|c|}{ Indications }} & \multicolumn{3}{c|}{ Factor } \\
\cline { 2 - 4 } & $1=30,8 \%$ & $2=18,4 \%$ & $3=18,4 \%$ \\
\hline Power & 0,908 & & \\
\hline Allowance & 0,824 & & \\
\hline $\begin{array}{l}\text { Escape from Problems in } \\
\text { Social Media }\end{array}$ & 0,759 & & \\
\hline Inflow of Forces & 0,631 & 0,609 & \\
\hline Problem Solving & & 0,763 & \\
\hline WHO-5 Well-being Index & $-0,533$ & $-0,631$ & \\
\hline Sleep disorders & 0,439 & $-0,528$ & \\
\hline Joy & & & 0,757 \\
\hline Diffuse Loneliness & & & $-0,725$ \\
\hline Relationship in the family & & & 0,552 \\
\hline
\end{tabular}

*The principal component method of rotation is varimax with Kaiser normalization

Thus, both factors included the following indicators: "Psychological well-being" and "Sleep disorder", which confirm the hypothesis that disturbances in the physical and psychological spheres occur with excessive involvement in the social network. This group of adolescents spends less than 2 hours a day in virtual communication, which favorably affects their 
psychological state. Adolescents receive communication, positive emotions and self-expression. Of great importance are the relationships in the family, which are recorded in the first and second factors, respectively. Harmonious relationships with the family minimize the need for adolescents to seek warmth and support on the internet, which has a major impact on psychological well-being.

Table 2

Two-factor matrix of components after rotation of group No. 2 (time spent online - more than 6 hours per day)

\begin{tabular}{|l|c|c|}
\hline \multirow{2}{*}{\multicolumn{1}{|c|}{ Indications }} & \multicolumn{2}{c|}{ Factor } \\
\cline { 2 - 3 } & $1=28,6 \%$ & $2=26,2 \%$ \\
\hline Inflow of Forces & 0,838 & \\
\hline Joy & 0,828 & \\
\hline Power & 0,815 & \\
\hline Allowance & 0,791 & \\
\hline Sleep Disorders & & 0,812 \\
\hline Diffuse Loneliness & & 0,707 \\
\hline WHO-5 Well-being Index & & $-0,686$ \\
\hline Relationship in the family & & $-0,594$ \\
\hline Escape from Problems in Social Media & & 0,490 \\
\hline Problem Solving & & 0,350 \\
\hline
\end{tabular}

Based on the distributed components in the first factor as shown in Table 2, it can be called "Emotions in social media". The over-involvement of adolescents on the social media is driven by a sense of freedom, understanding and belonging to the community.

The second factor has combined the Disadvantage construct, which can be explained by the fact that adolescents try to find support and understanding online that should boost their mood and self-esteem. However, despite this, adolescents suffer from psychological distress in the form of anxiety, loneliness, which is associated with low social support from family and friends. Such a pattern was elucidated in the work of scientists P. Maulick, K. Bradshaw. They found that people with low support were more prone to mental disorders than those with close relationships with family, neighbors, etc ${ }^{15}$.Trying to escape from problems, adolescents passively use social media, viewing posts, videos, photos of friends, which leads to the

${ }^{15}$ Maulik, P., Eaton, W., \& Bradshaw, C. (2011). The effect of social networks and social support on mental health services use, following a life event, among the Baltimore epidemiologic catchment area cohort. The Journal of Behavioral Health Services \& Research, 38 (1), 2950. URL: https://doi.org/10.1007/s11414-009-9205-z. 
appearance of envy, feelings of inferiority and the formation of manifestations of depression. According to the survey, preference for viewing social media at night before rest often causes the later (in rare cases, in the morning) sleep to become more restless and shorter, sometimes leading to insomnia.

The differences in the profiles of both groups of adolescents are due to time spent on social media, social motivation, family relationships and sleep patterns. All of the psychological factors involved are more critical to the formation of addiction.

\section{Individual-typological features of the influence of virtual communication on the adolescents' psychological well-being}

202 respondents, aged 15 to 22 years, participated in the study. The questionnaires mentioned in the second paragraph of this article were used. To assess psychological well-being more detailed The WarwickEdinburgh Mental Wellbeing Scale (WEMWBS) was added to the study. The main contingent of the study is represented by the age group of 16-20 years $(\mathrm{Mo}=17)$. Most of the respondents had only 2 social media accounts and no conflicts with others due to social network activity $(\mathrm{Mo}=2$ accounts, $\mathrm{Mo}=3$ points respectively). We have found that social media are the most popular among 17-year-olds. In our view, this can be explained by the crisis of adolescence, which is a period of individualization. This period is characterized by the development of moral consciousness, the active comparison of the ideal 'I' and real 'I', which is the basis of selfesteem. The need to find a place in life leads to an existential crisis. In this case, social media act as a source of finding oneself and contemplating the lives of others. Adolescents explore and alter their identities by choosing what information to share with others. Positive appreciation of others and acceptance into the global community can increase their self-esteem. With the free choice of creating an anonymous or real profile on social networks, adolescents can explore different styles of communication that for some reason (shyness, seclusion) may not be implemented in real life, search for answers to problematic or intimate questions. With an anonymous account, adolescents often share their creativity with the world without receiving feedback from their personality.

On the one hand, adolescents can express themselves and receive feedback, on the other, they become passive observers of other users' virtual lives. Browsing social media can both help to understand that adolescent is not alone in his or her experiences and problems, and provoke a sense of needlessness, anxiety over cyberbullying and isolation.

In a primary study, we found that the better relationship between adolescents and family members, the less time they spend on social media. 
This pattern has been confirmed by the second study. Adolescents use social media as a means of communicating with friends and family, as well as a platform for entertainment to get away from problems or to relax. On average, adolescents have 3 accounts in different social networks, which is explained by different functionalities. We found that modern adolescents prefer messengers (Viber, Telegram), Instagram, YouTube, and Facebook. The latter combines entertaining content, the ability to share their thoughts, creativity, life and socialize with others. This number of accounts can be called optimal because a large number of accounts on different platforms is quite a powerful stress factor that can lead to fear of missing out (FOMO), information overload, anxiety, and depression. The potential impacts listed can be explained by the need to update your profile, share something interesting, to encourage a large audience. The survey showed that modern adolescents started using social networks at an early age, with an average of 7 years of use $(6.96 \pm 0.171)$. This phenomenon demonstrates that social media have become an integral part of the adulthood of adolescents millennials. Respondents surveyed spend on average more than 3 hours a day on social networks $(2.88 \pm 0.076)$. This can be explained by the fact that thanks to smartphones, adolescents have $24 / 7$ access to social media, where different types of information exchange can keep in touch with other users. These types include text and voice messaging, various messengers and social networking applications (audio, video calls, discussion posts). Adolescents often prefer online communication rather than meeting friends. Online communication is more convenient, faster and does not require eye-contact, which to some extent facilitates interpersonal interaction for shy adolescents. However, the illusion of socialization provokes the development of loneliness and anxiety. Using social media as a platform to increase the number of acquaintances increases the level of alienation of the person as a whole in social relations, which leads to even more segregation as there is an excessive focus on the virtual world, which in turn pushes the problematic levels of Internet usage. The conducted research has allowed establishing that the circle of communication of adolescents in reality and social media is only partially identical. Adolescents use social media to communicate with relatives, study colleagues, and online audiences of their blogs. The results showed that modern adolescents, despite the need for communication, prefer the passive use of social media. This means that they are more or fewer observers of someone else's 'life'. During passive use, adolescents can post and evaluate other users' posts, watch the news feed, that is, consume information without contacting others. Passive involvement in social media has its consequences. Firstly, the difficulty of exiting social media. As you scroll through the news feed, you can find more and more interesting information that you need to browse right now. There is a situation where 
adolescents open a large number of links that attract their attention so much that it is very difficult to distract. Our study found that diverting attention to various news across social networking platforms sometimes leads to difficulty completing social media sessions $(2.69 \pm 0.067)$. Secondly, sleep disorder $(2.53 \pm 0.080)$ was noted in passive use in adolescents. This can be explained by the phenomenon of so-called "rabbit hole" content on platforms such as Instagram and YouTube. When looking at a large number of different photos and videos before bedtime, adolescents often find themselves looking at archival records or so-called "video lessons" and challenges that are so distracting which leads to poor sleep or its absence. As a result, adolescents have complaints about well-being and concentration. Thirdly, the passive use of it provokes the development of addiction, because at any time of the study, spending time with loved ones, feeling bored, adolescents automatically scroll through the news feed or watch other users' pages without even realizing that they are doing it.

The problem of loneliness and social media is a common issue of today. The data obtained allow us to establish that adolescents feel lonely $(7.76 \pm 0.215)$, characterized by a sense of psychological identity, selfidentity, which is conditioned by the correlation of identification and separation in connection with virtual communication.

For a detailed analysis of the impact of social media on the psychological well-being of adolescents, The Warwick-Edinburgh Mental Wellbeing Scale $(\alpha=0.85)$ was applied. The mean sample result $(\mathrm{M}=47.81, \pm \sigma=9.93)$ demonstrated the poor level of well-being of modern adolescents. This can be explained by the passive use of social media $(2.94 \pm 0.073)$, which provokes emotional lability, irritability, depression, and neglect of sleep to obtain more up-to-date information on various events and trends. Adolescents use social media as a means to feel involved in the community. However, the functionality of social networks in our time is not limited to communication, they provide an opportunity to look into the lives of registered users, creating the illusion of involvement and intimacy with others. Therefore, social media can potentially provide a sense of involvement, increasing satisfaction with virtual interpersonal communication. In reality, adolescents prefer to be observers or chat through posts or polls per page, which greatly reduces the ability to engage in productive communication. The latter can provoke mood swings, feelings of loneliness and increased levels of shyness in making contacts.

It can be assumed that the average severity of neuroticism in adolescents is associated with the need to improve their mood or escape from problems in the social media. Such behavior can provoke a violation of self-regulation, resulting in increased time spent on social media. The presence of spontaneous and reactive aggression is related to the content of social media, 
the specifics of online communication and the emotional state of teens. Depression is caused by the lack of expectations and the reality of one's online image, getting unwanted or lacking reactions to the post, feeling unresponsive and misunderstanding with the online community. Irritability in the context of virtual communication demonstrates a tendency to conflict as an attempt to justify its excessive involvement in social media. Adolescents are prone to being demonstrative, which is coupled with the desire to reduce social contact. Low communicability rates support the hypothesis that a large number of social media accounts correlates positively with low sociability. On average, adolescents have more than 2 social networking accounts, but they prefer the role of the observer, which eliminates the need to connect with other users. The interface of personal pages is constructed in such a way that the information about users, which includes their likes and hobbies, favorite places and works of art, including literature, music, etc. is presented in sufficient detail, which eliminates the need for communication to a greater extent. Excessive use of social media leads to anxiety and disorganization of behavior. According to the survey, it was found that adolescents have difficulty concentrating, confusing their own experiences and feeling lonely. It has been found that adolescents feel insecure, shy and tight in communication, prefer a small circle of real acquaintances, try not to get acquainted on social media.

The existing compensation theory of the use of the Internet claims that users can overuse devices connected to the Internet to combat negative moods or avoid their problems in real life ${ }^{16}$. Therefore, we can assume the presence of the relationship between stress and problematic social media use. In our study, it can be noted that social media are means of avoiding stress, not its source. Interviewed adolescents in a stressful situation behave quite restrained and regulate their own emotions without displaying them online $(3.03 \pm 0.126)$.

\section{CONCLUSIONS}

The need for approval from others at the expense of likes, comments leads to a constant desire to keep track of your page, anxiety, and feeling of loneliness. Diffuse loneliness is reinforced by the problem of adolescents' self-identification with other more popular users, which is often ambivalent. On the one hand, adolescents are confident in their content, on the other, they suffer from misunderstanding and emptiness. It should be noted that the conditional feeling of being part of a community depends on direct

\footnotetext{
${ }^{16}$ Kardefelt-Winther, D. (2014). A conceptual and methodological critique of Internet addiction research: Towards a model of compensatory Internet use. Computers in Human Behavior, 31, 351-354. DOI: 10.1016 / j.chb.2013.10.059
} 
interpersonal messages and comments. Considering the pattern of social media use by the interviewed adolescents, it can be noted that the passive use of social media, i.e. posting and expecting curses, reposts, etc., further delays adolescents in the excessive use of social media, which has a significant impact on the quality of life.

Therefore, the results obtained from the profiles of respondents allow to make this interim conclusion. Social media are essentially designed not only to communicate but also to save from boredom. Feeling pleasure and joy from being on social media is a strong incentive for their increasing use. Adolescents are very easily involved in a positive activity that provokes a strong production of dopamine in the brain. The principle of involvement in social media is based on the principle of behaviorists "stimulus-reaction". However, to distinguish hobbies from addiction, it should be borne in mind that the time spent on social media should bring a sense of ease and satisfaction, not the feeling of constant and intense checking of all accounts for updates.

Time spent online is inextricably linked to loneliness. Firstly, adolescents use social media as a means of improving interpersonal skills when it is impossible to make the desired contacts in reality, due to social anxiety and shyness. Secondly, the passive use of social media completely eliminates interactions with others, which creates the illusion of being involved in a large community, although interaction does not occur. The problem is that adolescents tend to identify with more popular users and ideas, which in turn produces the development of diffuse loneliness. Individual characteristics and motivation are also important for the presence or absence of loneliness through the use of social media. Some respondents are open-minded individuals with a wide range of communication, both online and in real life. Thus, social media can both replace real communication completely and help extend interaction with other people.

To summarize, it is important to note that psychological well-being needs to be assessed holistically, meaning that the interconnections of physical, mobile and virtual spaces are always taken into account. Social media have both advantages and disadvantages. Therefore, screening time and information should be selected to minimize adverse health effects. All hypotheses confirmed as a result of the study.

\section{SUMMARY}

The article is devoted to the relevant to modern society topic of the influence of social media on the psychological well-being of adolescents. This issue has not been sufficiently studied in both domestic and foreign works of scientists. The situation is constantly changing, so its assessment always seems relevant. The current study found that adolescents feel both 
positive (opportunities for social contacts, profitable to present themselves online), and negative (cyberbullying, isolation, ignoring) effects on psychological well-being due to social media use. We found that for adolescents social media is a platform for self-expression and passive communication, mostly with already established contacts. The illusion of involvement and importance for a large number of people raises mood, selfesteem, sense of self-importance and power, interest. However, adolescents, on the other hand, experience nervousness, fatigue, and envy, which in the long run can trigger anxiety and depression. Adolescents who spend more and more time on social media are at high risk of having negative consequences due to unhealthy attitudes towards popularity and the obsessive habit of constantly checking social media profiles and status updates. The psyche of adolescents is not fully formed, so negative factors of social media's influence lead to conflict situations and psychological disorders (anxiety, stress, loneliness and depression).

\section{REFERENCES}

1. Бабаева Ю.Д., Войскунский А.Е., Смыслова О.В. Интернет: воздействие на личность. URL: http://www.relarn.ru/human/pers.html. (дата обращения: 17.01.2018).

2. Вебер К.С., Пименова А.А. Сравнительный анализ социальных сетей. Вестник ТГУ. 2014. Т. 19, вып. 2. С. 634-635.

3. Войскунский А.Е. Психология и Интернет. Москва : Акрополь, 2010. 439 c.

4. Корчагина С.Г. Психология одиночества : учебное пособие. Москва : Московский психолого-социальный институт, 2008. 228 с.

5. Цифрова компетентність підлітків та батьків. / Г.У. Солдатова, Т.А. Нестик, Е.І. Расказова, Е.Ю. Зотов. Москва : Фонд розвитку Інтернету, 2013. $144 \mathrm{c}$.

6. Bech P. (2004). Measuring the dimensions of psychological general well-being by the WHO-5. QoL Newsletter, 32, 15-16.

7. Buffardi, E. L., \& Campbell, W. K. (2008). Narcissism and social networking web sites. Personality and Social Psychology Bulletin, 34, 1303-1314. https://doi.org/10.1177/0146167208320061.

8. Deci E. L. and Ryan R. (2008). M. Self-determination theory: a macrotheory of human motivation, development, and health. Canadian Psychology-Psychologie Canadienne. № 49(3). URL: https://doi.org/ 10.1037/0708-5591.49.1.14.

9. Fahrenberg, J., Hampel, R. \& Selg, H. (2010). Freiburger Persönlichkeitsinventar (8., erweiterte Aufl.). Göttingen: Hogrefe.

10. Farnan JM, Snyder SL, Worster BK, et al. Online medical professionalism: patient and public relations: policy statement from the 
American College of Physicians and the Federation of State Medical Boards. Ann Intern Med. 2013; 158 (8): 620-62. 10.7326/0003-4819-158-8201304160-00100.

11. Kardefelt-Winther, D. (2014). A conceptual and methodological critique of Internet addiction research: Towards a model of compensatory Internet use. Computers in Human Behavior, 31, 351-354. doi: 10.1016/j.chb.2013.10.059.

12. Maulik, P., Eaton, W., \& Bradshaw, C. (2011). The effect of social networks and social support on mental health services use, following a life event, among the Baltimore epidemiologic catchment area cohort. The Journal of Behavioral Health Services \& Research, 38(1), 2950. URL: https://doi.org/10.1007/s11414-009-9205-z.

13. Topp, Christian \& Østergaard, Søren \& Søndergaard, Susan \& Bech, Per. (2015). The WHO-5 Well-Being Index: A systematic review of the literature. Psychotherapy and psychosomatics, 84, 167-176. URL: https://doi.org/10.1159/000376585.

14. Turkle, S. (2011) Alone Together: Why we expect more from technology and less from each other. New York: Basic Books. URL: https://doi.org/10.1002/asi.22658

15. Wilson, K., Fornasier, S., \& White, K. M. (2010). Psychological predictors of young adults' use of social networking sites. Cyberpsychology, Behavior, and Social Networking, 13, 173-177. URL: https://doi.org/10.1089/cyber.2009.0094.

16. Yao, M. Z., \& Zhong, Z. J. (2014). Loneliness, social contacts and Internet addiction: A cross-lagged panel study. Computers in Human Behavior, 30, 164-170. URL: https://doi.org/10.1016/j.chb.2013.08.007.

Information about the author: Hudimova A. Kh.,

Ph.D. Candidate in Psychology, Department of Social Care and Practical Psychology Odesa I. I. Mechnikov National University 2, Dvoryans'ka str., Odesa, Ukraine 